\title{
Transient increase of raf protein kinase-like immunoreactivity in the rat dentate gyrus during long-term potentiation
}

\author{
András Mihály ${ }^{1}$, Zoltán Oláh ${ }^{2}$, Manfred Krug ${ }^{3}$, Ulrich Kuhnt ${ }^{1}$, \\ Hansjürgen Matthies ${ }^{4}$, Ulf R. Rapp ${ }^{5}$ and Ferenc Joo ${ }^{6}$ \\ 'Department of Neurobiology, Max Planck Institute for Biophysical Chemistry, Göttingen (F.R.G.), \\ 'Laboratory of Cellular Oncology, National Cancer Institute, National Institutes of Health, Bethesda, \\ MD 20892 (U.S.A.), 'Institute of Pharmacology, Medical Academy and ${ }^{4}$ Institute of Neurobiology and \\ Brain Research, Academy of Sciences of GDR, Magdeburg (G.D.R.), 'Laboratory of Viral Carcinogenesis, \\ NCI-Frederick Cancer Research Facility, Frederick, MD 21701 (U.S.A.) and ${ }^{6}$ Laboratory of Molecular \\ Neurobiology, Institute of Biophysics, Biological Research Center, Szeged (Hungary)
}

(Received 23 February 1990; Revised version received 18 March 1990; Accepted 23 April 1990)

Key words: Immunohistochemistry; Protooncogene; Protein kinase; Long-term potentiation; Dentate fascia

\begin{abstract}
Altered levels of cellular raf proteins (products of the raf protooncogenes) have been shown in the neurons of the dentate fascia of rats in response to high-frequency stimulation, with light microscopic immunohistochemistry by using polyclonal antibodies. No raf-1-like staining was seen in unstimulated tissue, while the pan-raf antibodies revealed immunoreactivity in the cytoplasm of neurons in the Ammon's horn and dentate fascia of rats and guinea pigs. The induction of long-term potentiation in the dentate fascia of freely-moving rats triggered the appearance of raf-1-like staining and increased the number of granule cells with pan-raf-like immunoreactivity. Since these proteins are serine/threonine-specific protein kinases, their appearance in long-term potentiation may indicate the activation of important cell membrane nucleus transduction pathways.
\end{abstract}

Hippocampal long-term potentiation (LTP) is characterized by a long-lasting increase in the efficiency of impulse transmission, following a short train of high-frequency stimuli to any one of the monosynaptic excitatory pathways (for review, see ref. 2). The maintenance of LTP is subserved by several biochemical processes among which the activation [12] and translocation [1] of the $\mathrm{Ca}^{2+} /$ phospholipid-dependent protein kinase (PKC) seemed to play a substantial role. Recently, an additional serine/threonine protein kinase, encoded by raf protooncogenes [11] has been proposed to regulate the downstream transfer of information from the plasma membrane to the nucleus in mitotically activated cell cultures $[8,11]$. Extending this proposal to

Correspondence: A. Mihály, Department of Neurobiology, MPI for Biophysical Chemistry, P.O. Box 2841, D-3400 Göttingen, F.R.G. 

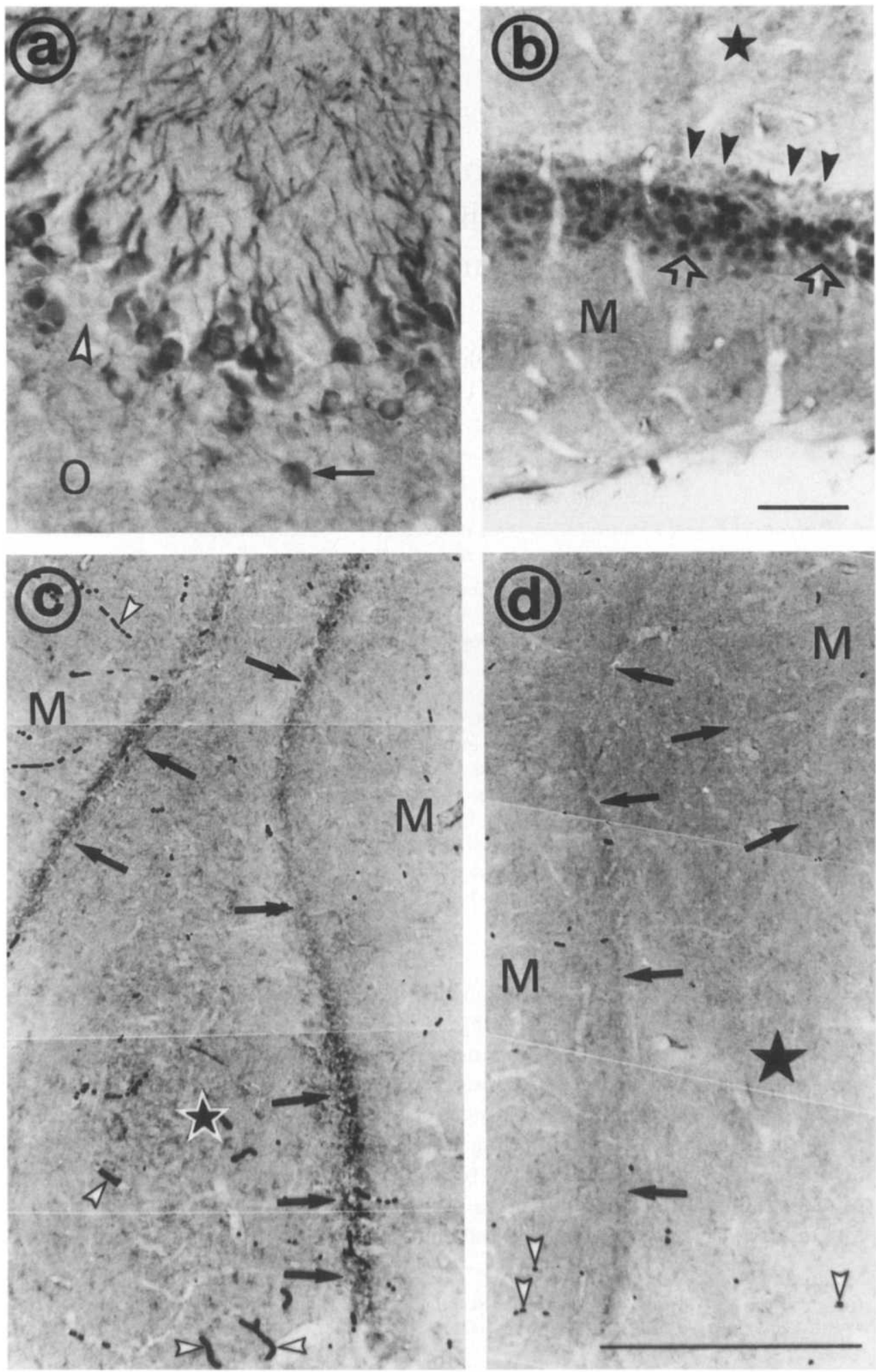
highly differentiated nervous tissue, as a first step, the localization of the products of the raf protooncogenes was investigated in the hippocampus of adult rats and guinea pigs. For this purpose polyclonal antibodies against raf proteins were used $[6,13]$. As a second step, we induced LTP in the dentate gyrus of freely moving rats and investigated the light microscopic immunohistochemical localization of raf proteins (the products of the raf protooncogenes) in the dentate gyrus.

Two male Wistar rats $(130 \mathrm{~g})$ and 2 male guinea pigs $(650 \mathrm{~g})$ were anesthetized with pentobarbital $(40 \mathrm{mg} / \mathrm{kg})$ and perfused transcardially with $4 \%$ paraformaldehyde, $0.1 \%$ glutaraldehyde in $0.1 \mathrm{M}$ phosphate buffer $(\mathrm{pH} 7.4)$. Forty- $\mu \mathrm{m}$-thick coronal sections were cut with Vibratome, washed in phosphate-buffered saline (PBS, pH 7.4) and treated with $0.5 \%$ sodium borohydride in PBS [16]. Consecutive sections were incubated with polyclonal raf-1 [13] and pan-raf antibodies [6]. The raf-1 antibodies were raised against the synthetic SP 63 peptide [13] which is the C-terminal sequence (12 amino acids) of the raf-1 protein [3]. The pan-raf antibodies were raised against a larger (approx. $30 \mathrm{kDa}$ ) C-terminal protein expressed in $E$. coli, by inserting the v-raf oncogene into the bacterial DNA [6]. The antibodies were diluted to 1:500, $1: 1000$ and 1:2000, the sections were incubated free-floating for $24 \mathrm{~h}$ at $4^{\circ} \mathrm{C}$, labelled by means of the avidin-biotin technique [4], and developed with diaminobenzidine$\mathrm{HCl}$ as a substrate. Control sections were incubated without the primary or secondary antibodies.

In order to test the effects of stimulation and LTP, 20 Wistar rats (160-170 g males) were chronically implanted with a pair of stimulating electrodes in the medial entorhinal cortex and a recording electrode in the dentate gyrus, as described previously [7]. The animals were conditioned without signs of seizures or afterdischarges until a pronounced LTP could be observed after biphasic stimulation (a train of $300 \mathrm{im}$ pulses in groups of 15 with $5 \mathrm{~s}$ intervals and $200 \mathrm{~Hz}$ ). LTP was induced in 10 animals. The controls (10 animals) were stimulated with constant current square wave pulses $(0.1 \mathrm{~ms}, 100-400 \mu \mathrm{A}, 0.2 \mathrm{~Hz})$. Altogether, 16 animals in pentobarbital anesthesia $(40$ $\mathrm{mg} / \mathrm{kg}$ ) were transcardially perfused with $4 \%$ paraformaldehyde and $0.1 \%$ glutaraldehyde in $0.1 \mathrm{M}$ phosphate buffer ( $\mathrm{pH} 7.4)$ at different times $(5,30,120$ and $240 \mathrm{~min}$ ) following the control and the high-frequency stimulations (2-2 animals at each time). Coronal plane serial frozen sections $(40 \mu \mathrm{m})$ were cut from the whole hippocampus between the electrodes, washed in PBS for 12-16 h and incubated free-floating with the two antisera - both diluted to $1: 3000$ - for $60 \mathrm{~h}$ at $4^{\circ} \mathrm{C}$. The other steps of the reaction were identical with that described above. On average 30 sections per brain

Fig. 1. Immunohistochemical detection of RPI with pan-raf $(a, b)$ and raf-1 (c,d) antibodies in the rat hippocampus ( $M$, molecular layer; asterisk, hilus of the dentate fascia). a: CA3 pyramidal cells containing RPI. Arrow point to interneuron in stratum oriens $(O)$. The neurons at the arrowhead are not immunoreactive. b: granule cells of the dentate fascia containing RPI (arrows). Arrowheads point to unstained neurons. Bar for $\mathrm{a}$ and $\mathrm{b}=100 \mu \mathrm{m}$. $\mathrm{c}$ : composit photograph of the dentate fascia $120 \mathrm{~min}$ after the induction of LTP. Strong immunostaining can be observed in the granular layer (arrows). Arrowheads point to red blood cells. $d$ : no immunoreactivity can be seen on the contralateral side of the same section (arrows: granular layer; arrowheads: red blood cells). Bar for $\mathrm{c}$ and $\mathrm{d}=0.5 \mathrm{~cm}$. 
were investigated. The immunostained cell bodies in the granular layer of the dentate gyrus were plotted at a $100 \times$ magnification with the help of an $x y$ plotter, then a $1 \mathrm{~mm}^{2}$ rectangle with one side parallel to the interhemispheric fissure was layed over the dentate fascia and the immunostained cells of the granular layer were counted. Since the electrodes were implanted stereotaxically, the serial frozen sections between the electrode tracks represented comparable series. The counting has been done on parallel sections, i.e. on sections bearing the same serial number. From each animal 5 sections were used for counting. In the case of raf-1-like immunoreactivity, no counting was performed.

The raf protein-like immunoreactivity (RPI) could be detected in neuronal cell bodies and dendrites in every subfield of the unstimulated hippocampal formation both in guinea pigs and rats, with the help of the pan-raf antibodies (Fig. 1). In the dentate gyrus the staining was mainly confined to neuronal cell bodies and sometimes neuronal cell nuclei of the granular layer (Fig. 1). Although most of the immunoreactive neurons were located in the pyramidal and granular layers, not all neurons of these layers contained RPI (Fig. 1). No attempts were made to estimate the ratio of stained:unstained neurons. Increasing dilutions of the antiserum resulted in a decrease of the staining intensity, indicating the specificity of the method [10]. The control sections incubated without the primary or secondary antibodies did not stain (except for some red blood cells). No RPI could be detected in the normal, unstimulated hippocampuses with the help of the raf-1 antibodies.

The overall pattern of RPI did not change after the different stimulation paradigms. No increase of staining was observed in the molecular layer of the dentate gyrus containing the nerve terminals of the perforant path [9]. However, stronger RPI was seen in the granular layer 120 min after the induction of LTP. The increase of staining was due to the increased number of granule cells containing RPI (Fig. 2). Interestingly enough, the number of immunostained cell bodies decreased thereafter, suggesting that the increase of RPI was transient (Fig. 2). No significant changes in the number of immunoreactive granule cells were seen in the contralateral, non-stimulated hippocampuses and following control stimulation (Fig. 2).

No RPI could be detected in the hippocampuses stimulated with control stimuli with the help of the raf -1 antibodies. However, strong immunostaining appeared 120 min after the induction of LTP, on the side of stimulation (Fig. 1). The staining outlined the granular layer in the otherwise unstained hippocampal formation (Fig. 1) and was due to a population of granule cells. The staining also disappeared at 240 min and was not seen on the contralateral side (Fig. 1).

Our immunohistochemical experiments for the first time localized raf proteins in the highly differentiated, adult nervous tissue. The immunoreactivity was mainly confined to the cytoplasm of the neurons which finding is in agreement with recent biochemical data [8, 14], and immunohistochemical localization studies performed on NIH 3T3 fibroblast cultures [11]. Our experiments with tetanized animals suggested the elevation of neuronal raf protein levels during the maintenance of LTP. The transient elevation was very obvious in the case of pan-raf antibodies, but not so with raf-1-like staining, since the latter could not be detected in non-stimulated neurons. 


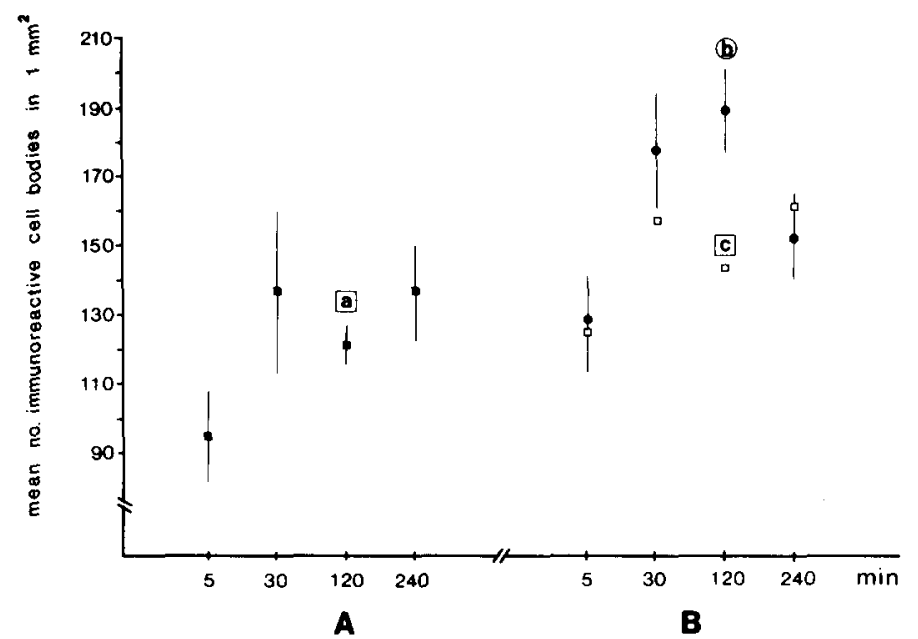

Fig. 2 Graph showing the average number of cell bodies containing pan-raf-like staining in the granular layer of the dentate fascia. Each point is the average of 10 measurements. A shows the counts in different time intervals after control, low frequency stimulation ( $\boldsymbol{D})$. B contains the counts after tetanization $(\boldsymbol{Q})$. The counts taken from the contralateral, unstimulated side are also depicted without the standard deviations ( $\square)$. Differences between a and $\mathrm{b}(t=8.5 ; P=0.001$, and $\mathrm{b}$ and $\mathrm{c}(t=3.2 ; P=0.05)$ are significant

The RNA expression patterns of raf- 1 in the mouse brain showed the highest level in the cerebellum, and only moderate (just above the detectable) levels in other parts of the brain [15]. This might explain the fact that RPI was not seen in the normal hippocampus. The raf-1 antibodies are very specific, since the SP 63 peptide is not present in other proteins of the raf family $[5,11]$. Our results obtained in tetanized animals suggested the increase of $r a f-1$ protein levels in the dentate gyrus. Due to this increase the RPI became detectable in our experiments.

The pan-raf antibodies, on the other hand, reacted not only with the raf-1 protein [14], but also with the B-raf protein [5] which should be a par excellence brain-related protein as shown by the RNA expression pattern [15]. On the basis of this and the similarities of the amino acid sequences [5], we think that the RPI detected with panraf antibodies should mainly be the B-raf-like staining. However, this has to be corroborated by reacting the tissue with specific B-raf protein antibodies. This work is in progress in our laboratory.

Miss K. Kaiser and Mrs. M. Wagner (Magdeburg) provided excellent technical assistance. A.M. is a recipient of a fellowship from Alexander von Humboldt Foundation.

1 Akers, R.F., Lovinger, D.M., Colley, P.A., Linden, D.J. and Routtenberg, A., Translocation of protein kinase C activity may mediate hippocampal long-term potentiation, Science, 231 (1986) 587-589.

2 Bliss, T.V.P. and Lynch, M.A., Long-term potentiation of synaptic transmission in the hippocampus: properties and mechanisms. In P.W. Landfield and S.A. Deadwyler (Eds.), Long-Term Potentiation: From Biophysics to Behavior, Alan R. Liss, New York, 1988, pp. 3-72. 
3 Bonner, T.I., Oppermann, H., Seeburg, P., Kerby, S.B., Gunnell, M.A., Young, A.C. and Rapp, U.R., The complete coding sequence of the human raf oncogene and the corresponding structure of the c-raf1 gene, Nucleic Acids Res., 14 (1986) 1009-1015.

4 Hsu, S.-M., Raine, L. and Fanger, H.J., Use of avidin-biotin-peroxidase complex (ABC) in immunoperoxidase techniques: a comparison between $\mathrm{ABC}$ and unlabelled antibody (PAP) procedures, J. Histochem. Cytochem., 29 (1981) 577-580.

5 Ikawa, S., Fukui, M.. Ueyama, Y., Tamaoki, N., Yamamoto, T. and Toyoshima, K., B-raf, a new member of the raf family, is activated by DNA rearrangement, Mol. Cell. Biol., 8 (1988) 2651-2654.

6 Kolch, W., Schultz, A.M., Oppermann, H. and Rapp, U.R., Preparation of raf-oncogene-specific antiserum with raf protein produced in E. coli, Biochim. Biophys. Acta, 949 (1988) $233-239$.

7 Krug, M., Brödemann. R. and Ott, T., Blockade of long-term potentiation in the dentate gyrus of freely moving rats by the glutamic acid antagonist GDEE, Brain Res., 249 (1982) 57-62.

8 Morrison, D.K., Kaplan, D.R., Rapp. U. and Roberts, T.M., Signal transduction from membrane to cytoplasm: growth factors and membrane-bound oncogene products increase raf-1 phosphorylation and associated protein kinase activity, Proc. Natl. Acad. Sci. U.S.A., 85 (1988) 8855-8859.

9 Nafstad, P.H.J., An electron microscope study on the termination of the perforant path fibres in the hippocampus and the fascia dentata, Z. Zellforsch., 76 (1967) $532-542$.

10 Petrusz, P., Ordonneau, P. and Finley, J.C.W., Criteria of reliability for light microscopic immunocytochemical staining, Histochem. J., 12 (1980) 333-348.

11 Rapp, U.R., Heidecker, G., Huleihel, M., Cleveland, J.L., Choi, W.C., Pawson, T., Ihle, J.N. and Anderson, W.B., Raf family serine/threonine protein kinases in mitogen signal transduction, Cold Spring Harbor Symp. Quant. Biol., 53 (1988) 173-184.

12 Reymann, K.G., Schulzeck, K., Kase, H. and Matthies, H., Phorbol ester-induced hippocampal longterm potentiation is counteracted by inhibitors of protein kinase C, Exp. Brain Res.. 71 (1988) 227 230.

13 Schultz, A.M.. Copeland, T.D., Mark, G.E., Rapp, U.R. and Oroszlan, S., Detection of the myristilated gag-raf transforming protein with raf-specific antipeptide sera, Virology, 146 (1985) 78-89

14 Schultz, A.M., Copeland, T.D., Oroszlan, S. and Rapp, U.R., Identification and characterization of c-raf-phosphoproteins in transformed murine cells, Oncogene, 2 (1988) 187-193.

15 Storm, S.M., Cleveland, J.L. and Rapp, U.R., Expression of raf family proto-oncogenes in normal mouse tissues, Oncogene, 5 (1990) $101-107$

16 Willingham, M.C. An alternative fixation-processing method for preembedding ultrastructural immunocytochemistry of cytoplasmic antigens: the GBS (glutaraldehyde-borohydride- saponin) procedure, J. Histochem. Cytochem., 31 (1983) $791 \cdots 798$. 